\title{
Immediate Release Tablet Dosage Form
}

National Cancer Institute

\section{Source}

National Cancer Institute. Immediate Release Tablet Dosage Form. NCI Thesaurus.

Code C142248.

A tablet dosage form that is designed to release its active and/or inert ingredient(s) upon administration with no enhanced, delayed or extended release effect. 